\title{
10 ANOS DO SISTEMA DISTRITAL DE UNIDADES DE CONSERVAÇÃO DA NATUREZA: AVANÇOS E RETROCESSOS
}

\author{
Lorene Raquel de Souza* \\ Márcia Dieguez Leuzinger* \\ Paulo Campanha Santana*
}

\section{Resumo:}

O Sistema Distrital de Unidades de Conservação da Natureza, criado pela Lei Complementar $n^{\circ} 827$, de 22 de julho de 2010, está completando uma década com avanços e retrocessos. O objetivo do presente artigo, portanto, é avaliar as principais evoluções e involuções, com foco nos desafios que ainda permeiam a implementação desse sistema protetivo.

Palavras-chave: Unidades de Conservação. Conservação da biodiversidade. Avanços. Retrocessos.

\section{YEARS OF THE DISTRICT SYSTEM OF NATURE CONSERVATION UNITS: ADVANCES AND RETROCESSES}

\begin{abstract}
:
The District System of Nature Conservation Units, created by Complementary Law No. 827, of July 22, 2010, is completing a decade with advances and setbacks. The aim of this article, therefore, is evaluate the main evolutions and involutions, focusing on the challenges that still permeate the implementation of this protective system.
\end{abstract}

Keywords: Conservation Units. Biodiversity Conservation. Advances. Setbacks.

\section{Introdução}

\footnotetext{
* Graduada em Direito pela Universidade Católica de Brasília, (Brasília - DF, Brasil). Mestre em Direito e Políticas Públicas pelo Centro Universitário de Brasília - Uniceub, (Brasília - DF, Brasil). Analista de Atividades do Meio Ambiente, especialidade Advogada, do Instituto do Meio Ambiente e dos Recursos Hídricos do Distrito Federal, (Brasília - DF, Brasil). Coordenadora do Grupo de Pesquisa em Direito Ambiental e Desenvolvimento Sustentável do Centro Universitário de Brasília - Uniceub, (Brasília - DF, Brasil). Endereço para correspondência: QR 408, conjunto 7, casa 14, Samambaia Norte - DF. CEP: 72318-307. E-mail: lorene.raquel@gmail.com.

* Graduação em Direito pela Universidade Cândido Mendes (Rio de Janeiro, RJ, Brasil), Mestre em Direito e Estado e Doutora em Desenvolvimento Sustentável pela Universidade de Brasília - UnB, (Brasília - DF, Brasil), Pós-Doutora pela University of New England, (Armidale -NSW, Austrália), Professora de Direito Ambiental da graduação, do Mestrado e do Doutorado em Direito do Centro Universitário de Brasília - UniCEUB, (Brasília DF, Brasil), Procuradora do Estado do Paraná em Brasília (Procuradoria Geral do Estado do Paraná, Brasília DF, Brasil), Líder do Grupo de Pesquisa em Direito Ambiental e Desenvolvimento Sustentável do Centro Universitário de Brasília - Uniceub, (Brasília - DF, Brasil). E-mail: marcia.leuzinger@uol.com.br.

* Advogado, Mestre e Doutor em Direito pelo Centro Universitário de Brasília -UniCEUB, Distrito Federal (Brasília-DF, Brasil), Professor e Coordenador do Curso de Direito do Centro Universitário do Distrito Federal UDF (Brasília-DF, Brasil). E-mail: pcampanhap@gmail.com.
}

Rev. de Direito e Sustentabilidade | e-ISSN: 2525-9687 | Evento Virtual | v. 6 | n. 1 | p. 16-36 |

Jan/Jun. 2020 
A noção de sustentabilidade pressupõe tradicionalmente a convivência harmônica entre as esferas econômica, social e ambiental. Esse entrosamento, no entanto, não é fácil. Por isso, no Brasil, a Constituição Federal previu expressamente no artigo 225 que umas das formas de se assegurar a efetividade do direito ao meio ambiente ecologicamente equilibrado, pilar ambiental da sustentabilidade, é por meio da instituição de Espaços Territoriais Especialmente Protegidos - ETEPs.

Os denominados ETEPs são áreas gravadas de proteção jurídica pelo Poder Público com o objetivo de preservar os atributos ambientais que lhes são inerentes. A criação desses espaços, que incluem as Unidades de Conservação - UCs, é importante porque a busca pela sustentabilidade sob o ponto de vista ambiental demanda, ao mesmo tempo, o uso racional dos recursos naturais e a necessidade de preservar da biodiversidade.

Essa obrigação, no entanto, não está restrita à União, recaindo também sobre os Estados, Municípios e Distrito Federal, conforme determina a própria Constituição.

Ciente desse múnus, o Distrito Federal, com base na Constituição, na Lei no 9.985, de 18 de julho de 2000, que instituiu o Sistema Nacional de Unidades de Conservação da Natureza - SNUC, na Lei Orgânica do Distrito Federal e na Lei Distrital no 041/89, que versa sobre a Política Distrital de Meio Ambiente, editou o seu próprio Sistema Distrital de Unidades de Conservação da Natureza - SDUC.

A Lei Complementar Distrital $n^{\circ}$ 827, de 22 de julho de 2010, responsável pela instituição do SDUC, replicou a maior parte dos dispositivos do sistema nacional, tendo inovado com relação à criação da categoria de Parque Ecológico, à exclusão das denominadas de Reserva Extrativista e de Reserva de Desenvolvimento Sustentável e à destinação dos recursos de compensação ambiental, que não é exclusivo das unidades de conservação de proteção integral, como ocorre na esfera federal.

Passados dez anos desde a sua edição, no entanto, é preciso fazer um balanço sobre os avanços e os retrocessos do SDUC, com foco nos desafios que ainda permeiam a implementação desse sistema protetivo.

A recategorização, que é a adequação da nomenclatura de uma unidade àquelas previstas na Lei, observada à realidade fática e ambiental de cada área, talvez tenha sido o avanço mais significativo. Aos poucos, os Plano de Manejo, que são os documentos técnicos que norteiam a utilização e a preservação desses espaços, também estão sendo editados, assim 
como os atos legais responsáveis pela recriação formal de várias unidades, que não tinham a sua constituição jurídica regular.

A inatividade dos Conselhos Gestores e a indefinição das poligonais de algumas Unidades de Conservação refletem a paralisia que se abate sobre alguns mandamentos legais da Lei distrital, que pregam a necessidade de implementação do primado da participação popular e de definição dos limites físicos desses espaços.

Os desafios ainda são imensos. Além do equacionamento da ausência de participação social e de contornos físicos de algumas UCs, há outras questões que precisam ser equacionadas, como por exemplo, a instalação das estruturas básica de gestão, que embora não seja objeto do presente trabalho, merece ser citada.

A proposta do presente artigo é abordar os aspectos mais relevantes do Sistema Distrital de Unidades de Conservação da Natureza, nesses últimos 10 anos, por meio da análise de vários diplomas legais, como a Lei Federal n 9.985, 18 de julho de 2000, e, em especial, a Lei Complementar Distrital n 827, de 22 de julho de 2010, e das informações inseridas no sítio eletrônico do Instituto do Meio Ambiente e dos Recursos Hídricos - Brasília Ambiental - IBRAM/DF., que é o ente responsável por gerir as UCs distritais.

A Lei de Acesso à Informação - LAI também foi um importante instrumento para a obtenção de dados e de vários outros documentos junto ao IBRAM e à Secretaria de Estado de Meio Ambiente para robustecer a pesquisa.

\section{Breves considerações sobre a relação existente entre a criação de Espaços Territoriais Especialmente Protegidas e a sustentabilidade.}

O ideário de sustentabilidade nasceu associado ao viés ecológico, por refletir a capacidade de resiliência dos ecossistemas frente às agressões naturais ou não, e econômico, ao qualificar a palavra desenvolvimento, incorporando a ela a premissa de racionalidade dos recursos ante a percepção de sua esgotabilidade (NASCIMENTO, 2012).

Com o aprofundamento dos debates sobre a gravidade da situação ambiental mundial ${ }^{\dagger}$, na Conferência das Nações Unidas sobre o Meio Ambiente Humano, em

\footnotetext{
† A questão ambiental passou a ser objeto de atenção internacional devido ao agravamento de eventos potencialmente danosos, envolvendo, por exemplo, a poluição atmosférica e o uso de agrotóxicos (POTT; ESTRELA, 2017).
}

Rev. de Direito e Sustentabilidade | e-ISSN: 2525-9687 | Evento Virtual | v. 6 | n. 1 | p. 16-36 | 
Estocolmo, na Suécia, em 1973, e na Conferência das Nações Unidas sobre o Meio Ambiente e o Desenvolvimento, realizada no Rio de Janeiro, em 1992, incorporou-se à sustentabilidade o aspecto social. Assim, a sustentabilidade ou desenvolvimento sustentável passou a ter como pressuposto tradicional três aspectos: o econômico, o social e o ambiental.

Sob o ponto de vista ambiental, a sustentabilidade é "um atributo necessário no tratamento dos recursos ambientais, em especial dos recursos naturais" (MILARÉ, 2015), demandando a concretização de ações destinadas a sua manutenção, preservação e racionalização.

A comunidade científica aponta que uma das formas mais eficientes de se proteger a diversidade biológica ${ }^{\ddagger}$ é por meio da instituição de Espaços Territoriais Especialmente Protegidos - ETEP (LEUZINGER, 2009).

Esse movimento, no entanto, não é novo. Leuzinger (2009) destaca que as primeiras medidas destinadas a criação de reservas são anteriores ao período cristão, embora os espaços, nos moldes atuais, tenham surgido no final do século XIX.

Desde então, a ideia passou a ser a proteção de áreas com atributos ambientais sensíveis (DIEGUES, 1996) visando à manutenção da sustentabilidade desses recursos naturais (BENSUSAN, 2006).

Dentro desse contexto, a Constituição Federal (1988) passou a reconhecer a importância desses espaços, impondo ao Poder Público o dever de instituir, em todas as suas esferas de Poder, os denominados ETEPs, que somente podem ser alterados ou suprimidos por Lei, sendo proibido qualquer uso que comprometa a integridade dos atributos que justificaram sua proteção.

Posteriormente, após a modificação promovida pela Lei $n^{\circ} 7.804$, de 18 de julho de 1989, a criação de ETEPs também passou a ser um instrumento da Política Nacional de Meio Ambiente, instituída pela Lei $n^{\circ} 6.938$, de 31 de agosto de 1981.

São exemplos de ETEPs: Unidades de Conservação, jardins botânicos, jardins zoológicos, hortos florestais, áreas de preservação permanente, áreas de reserva legal, zonas de amortecimento de unidades de conservação, corredores ecológicos, reservas da biosfera, além de terras indígenas e territórios quilombolas (LEUZINGER, 2010).

\footnotetext{
\# A diversidade biológica, nos termos do artigo $2^{\circ}$, inciso a variabilidade de organismos vivos de todas as origens, compreendendo, dentre outros, os ecossistemas terrestres, marinhos e outros ecossistemas aquáticos e os complexos ecológicos de que fazem parte; compreendendo ainda a diversidade dentro de espécies, entre espécies e de ecossistemas;
} 
Dos Espaços Territoriais Especialmente Protegidos existentes, as Unidades de Conservação são a espécie mais difundida (SOUZA, 2017). O artigo $2^{\circ}$, inciso I, da Lei $\mathrm{n}^{\circ}$ 9.985/2000 define as UCs, nos seguintes termos:

I - Espaço territorial e seus recursos ambientais, incluindo as águas jurisdicionais,
com características naturais relevantes, legalmente instituído pelo Poder Público,
com objetivos de conservação e limites definidos, sob regime especial de
administração, ao qual se aplicam garantias adequadas de proteção;

Por força do Sistema Nacional de Unidade de Conservação - SDUC, no Brasil, existem dois grupos de UCs: Proteção Integral, cujo objetivo é preservar a natureza por meio, apenas, do uso indireto dos seus recursos naturais, e Uso Sustentável, que visa compatibilizar conservação da natureza com o uso sustentável de parcela dos seus recursos naturais (BRASIL, 2000).

Fazem parte das unidades federais de Proteção Integral: as Estações Ecológicas, as Reservas Biológicas, os Parques Nacionais, os Monumentos Naturais e os Refúgios de Vida Silvestre. Já o grupo de Uso Sustentável é composto pelas Áreas de Proteção Ambiental, Áreas de Relevante Interesse Ecológico, Florestas Nacionais, Reservas Extrativistas, Reservas de Fauna, Reservas de Desenvolvimento Sustentável e Reservas Particulares do Patrimônio Natural (BRASIL, 2000).

Além das UCs federais, o SNUC também é composto pelas unidades estaduais e municipais, sendo permitido a esses entes, de forma excepcional e a critério do Conama, a criação de categoriais próprias para atender as especificidades regionais ou locais.

Por se tratar de uma norma de caráter geral, entende-se, no entanto, que os sistemas de proteção eventualmente instituídos pelos Estados, Distrito Federal e Municípios devam ser editados em consonância com a Lei $n^{\circ}$ 9.985/2000 (SOUZA, 2017), até porque é preciso observar as diretrizes e os objetivos de preservação e sustentabilidade traçados para o sistema como um todo.

\section{Os principais avanços do SDUC nos últimos 10 anos: recategorização de grande parte das UCs, elaboração de diversos Planos de Manejo e a recriação de novas Unidades.}

O Distrito Federal, atendendo ao mandamento constitucional, editou o seu próprio Sistema Distrital de Unidades de Conservação da Natureza - SDUC, por meio da Lei Complementar $\mathrm{n}^{\circ} 827$, de 22 de julho de 2010. 
O Sistema Distrital guarda, em sua maior parte, consonância com o Sistema Nacional de Unidades de Conservação da Natureza - SNUC. Algumas inovações, no entanto, se fazem presente como a criação da categoria denominada de Parque Ecológico e a eliminação das Reservas Extrativistas e Reservas de Desenvolvimento Sustentável. Além disso, a destinação dos recursos de compensação ambiental não é exclusiva para as unidades de conservação de proteção integral, como acontece na esfera federal.

Assim, compõem as Unidades de Conservação Distritais, as Estações Ecológicas, as Reservas Biológicas, os Parques Distritais, os Monumentos Naturais e os Refúgios de Vida Silvestre, que são categorias do grupo de Proteção Integral. As Áreas de Proteção Ambiental, as Áreas de Relevante Interesse Ecológico, as Florestas Distritais, os Parques Ecológicos, as Reservas de Fauna e as Reservas Particulares do Patrimônio Natural ${ }^{\S}$ fazem parte do grupo categorizado como Uso Sustentável.

Até 2017, Souza (2017) explica que, levando-se em consideração apenas as UCs com atos constitutivos válidos, existiam no Distrito Federal 60 (sessenta) Unidades de Conservação, sendo que 10 (dez) unidades pertenciam ao grupo de Proteção Integral e 50 (cinquenta) integravam o grupo de Uso Sustentável. Havia ainda outras 27 (vinte e sete) áreas, que recebiam apenas a denominação de parque e, portanto, não eram enquadradas como UCs, além de 6 (seis) áreas que tiverem seus atos constitutivos declarados inconstitucionais (SOUZA, 2017).

Passados dez anos da criação do SDUC e quatro anos do retrato feito por Souza (2016), o quadro ambiental das Unidades de Conservação do Distrito Federal evoluiu significativamente. Hoje, existem 22 (vinte e duas) Unidades de Proteção Integral, sendo 2 (duas) Estações Ecológicas, 4 (quatro) Reservas Biológicas, 2 (dois) Monumentos Naturais, 7 (sete) Parques Distritais e 7 (sete) Refúgios de Vida Silvestre, e 51 (cinquenta e uma) UCs de Uso Sustentável, divididas entre 4 (quatro) Áreas de Proteção Ambiental, 12 (doze) Áreas de Relevante Interesse Ecológico, 1 (uma) Floresta Distrital e 34 (trinta e quatro) Parques Ecológicos (IBRAM, 2020) ${ }^{* *}$.

\footnotetext{
$\S$ No momento, não existem no DF as categorias denominadas de Reservas de Fauna e Reservas Particulares do Patrimônio Natural. IBRAM. Unidades de Conservação. Disponível em: http://www.ibram.df.gov.br/unidadesde-conservacao/. Acesso em: 27 mar. 2020.

** No site do IBRAM, constam 37 (trinta e sete) Parques Ecológicos. Três deles, no entanto, Parque Ecológico e Vivencial Sobradinho (ADI 16680-8/2013), Parque Ecológico da Cachoeirinha (ADI 756-4/2007) e o Parque Recreativo e Ecológico Canela de Ema (ADI 8012-4/2015) tiverem seus atos constitutivos declarados
} 
O número de áreas que recebiam apenas a denominação de parque, sem carregar, contudo, o atributo de ecológico, o que impedia a sua caracterização como UC, caiu para 16 (dezesseis $)^{\dagger \dagger}$. De igual modo, diminuiu também a quantidade de áreas irregulares devido à declaração de inconstitucionalidade de seus atos de criação. Antes eram 6 (seis), hoje são apenas 4 (quatro) porque duas unidades foram recriadas.

O aumento do número de Unidades de Conservação Distritais e a recriação de duas novas áreas são frutos do processo de recategorização, que foi iniciado no ano de 2014, em cumprimento ao artigo 46, da Lei Complementar $n^{\circ} 827 / 2010$, que assinalou o prazo de 180 (cento e oitenta) dias para que todas as áreas criadas antes da referida norma fossem avaliadas e adequadas ao SDUC.

Recategorizar significa adequar a nomenclatura das áreas existentes àquelas previstas em Lei, no caso do DF, à Lei Complementar no 827 de 22 de junho de 2010, adaptando-as à categoria mais indicada, de acordo com os seus atributos ambientais e características de uso atual (IBRAM, 2014).

Para cumprir tal intento, o ente ambiental distrital avaliou cada área protegida do Distrito Federal no intuito de verificar se o espaço estava inserido dentro de outra Unidade de Conservação, a fitofisionomia (vegetação do bioma cerrado), a presença de área de proteção de manancial, se o local estava inserido no entorno de outra UC, o tipo de uso, se havia a presença de ocupações, qual a infraestrutura de gestão e uso público e, é claro, quais atributos ambientais sensíveis eram inerentes ao local (IBRAM, 2014).

Após esse levantamento técnico, o ente ambiental distrital realizou consulta pública, com ampla divulgação e apoio de diversas entidades (MPDFT, 2015). Entre o término desse processo de publicização e a edição dos primeiros atos normativos, responsáveis por

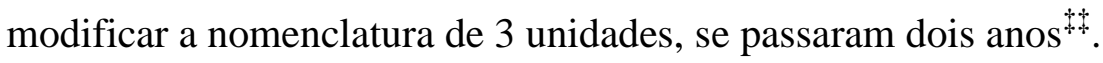

\footnotetext{
inconstitucionais e, portanto, precisam ser recriados. Por conta disso, essas UCs não foram contabilizadas no presente trabalho.

${ }^{\#} \mathrm{O}$ artigo 12, da Lei Complementar $\mathrm{n}^{\circ}$ 961, de 26 de dezembro de 2020, prevê que "os parques que tenham sido instituídos ou recategorizados na forma de parques de uso múltiplo, nos termos da Lei Complementar ${ }^{\circ}$ 265, de 14 de dezembro de 1999, passam a ser categorizados como parques urbanos".

$\$$ O Decreto $\mathrm{n}^{\circ} 38.367$, de 26 de julho de 2017, recategorizou o Parque Boca da Mata para Parque Distrital Boca da Mata, o Decreto $\mathrm{n}^{\circ}$ 38.368, de 26 de julho de 2017, recategorizou o Parque dos Jequitibás para Parque Ecológico dos Jequitibás e o Decreto ${ }^{\circ}$ 38.371, de 27 de julho de 2017, recategorizou o Parque Vivencial Pinheiro para Floresta Distrital Pinheiros.
} 
Em seguida, vivenciou-se um novo período de estagnação ${ }^{\S \S}$, que somente foi interrompido em 2019 com a edição do Decreto $n^{\circ}$ 40.116, de 19 de setembro de 2019, da Lei Complementar $n^{\circ} 955$, de 28 de novembro de 2019, e da Lei ${ }^{\circ} 6.414$, de 3 de dezembro de 2019, que adequaram a tipologia de 26 Unidades de Conservação.

A implementação dessa medida vai além do mero cumprimento da exigência prevista no artigo 46, da Lei Complementar $n^{\circ} 827 / 10$. Isso porque a recategorização trouxe para as unidades contempladas regularidade quanto às diretrizes protetivas e de uso, além de segurança jurídica para a atuação do Estado no que se refere à aplicação de recursos de compensação ambiental, que somente podem ser aplicados nas UCs, e ao desempenho, por exemplo, da atividade fiscalizatória, uma vez que o regime jurídico das UCs é muito mais severo sob o ponto de vista punitivo.

A recriação do Parque Ecológico de Águas Claras (DISTRITO FEDERAL, 2018) e do Parque Ecológico do Gama (DISTRITO FEDERAL, 2019) também se afiguram como avanços relevantes por trazer proteção jurídica à realidade fática e ambiental já insaturadas nessas áreas. A UC de Águas Claras, por exemplo, é uma das mais visitadas do Distrito Federal (SOUZA, 2017). Apesar disso, a sua recriação ocorreu 9 anos após a declaração de inconstitucionalidade de seu ato constitutivo inicial ${ }^{* * *}$. Já a Lei $\mathrm{n}^{\mathrm{o}} 1.959 / 98$, que criou o Parque Urbano e Vivencial do Gama, foi declarada inconstitucional em $2008^{\text {t† }}$, de modo que, entre essa data e edição do novo ato de criação, se passaram 11 anos.

Ambas as unidades, foram recriadas mediante a observância dos regramentos legais: confecção de estudo técnico e a realização de consulta pública ${ }^{\dagger+}$, conforme exige o artigo 21 , do SDUC.

\footnotetext{
$\$ \S$ Por conta desse período de estagnação, o Conselho Comunitário do Lago Sul ajuizou a Ação Civil Pública no 0703504-83.2019.8.07.0018 com o objetivo de condenar o Distrito Federal executar o plano de recategorização de suas unidades de conservação do Distrito Federal. A sentença, que julgou procedente o pleito, foi publicada no dia 9 de janeiro de 2020. O processo, atualmente, está em fase de recurso. TJDFT. DF deve recategorizar unidades de conservação e evitar riscos ambientais. Disponível em: https://www.tjdft.jus.br/institucional/imprensa/noticias/2020/janeiro/justica-determina-que-df-execute-plano-derecategorizacao-das-unidades-de-conservacao. Acesso em: 25 mar. 2020.

*** O ato constitutivo inicial - Lei Complementar $\mathrm{n}^{\circ}$ 287/2000 - do Parque Ecológico de Águas Claras foi declarado inconstitucional no âmbito da ADIN n 2050-8/2010.

\#† O ato constitutivo inicial do Parque do Gama - Lei $\mathrm{n}^{\circ} 1.959 / 1998$ - foi declarado inconstitucional no âmbito da ADIN no 2008.00.2.011819-3.

\#\# A Consulta pública também é necessária, por força do artigo 22, do SDUC, para a criação de novas UCs. Tal regra, porém, não se aplica às Estações Ecológicas e às Reservas Biológicas. Leuzinger explica que a Lei não exige consulta pública para a criação de Estação Ecológica e de Reserva Biológica porque dificilmente a população local concordaria com a instituição dessas categorias, que são muito restritivas e não admitem sequer
} 
O estudo técnico, destinado à criação de qualquer Unidade de Conservação, deve conter, além dos atributos ambientais, elementos que permitam identificar a localização, a categoria, a dimensão e, é claro, os limites da área que se pretende criar (DISTRITO FEDERAL, 2012).

Por força da expressa disposição contida no Sistema Distrital de Unidades de Conservação da Natureza, não se admite mais a mera indicação do local onde o espaço protegido está sendo instituído, prática que era comum no âmbito federal e distrital (SOUZA, 2017).

Como já foi mencionado, tanto a criação como a recategorização de Unidades de Conservação se apresentam como ações importantes porque, nos dias hodiernos, as UCs são consideradas umas das principais estratégias de conservação da biodiversidade no Ocidente (BENSUSAN, 2006).

A instituição de Unidades de Conservação, no entanto, ou até mesmo a eventual mudança de categoria, pode ser considerada uma missão menos árdua do que a adoção de iniciativas destinadas a implementação desses espaços, o que certamente envolve o dispêndio de muitos recursos. Bensusan (2006) pontua que a criação de UCs é mais chamativa sob a perspectiva eleitoral, já que as medidas de implementação ocorrem silenciosamente.

Dentro desse contexto, a construção de novos Planos de Manejo é uma iniciativa que merece ser comemorada porque é por meio deste documento, que as normas de uso e manejo dessas áreas são estabelecidas, assim como a infraestrutura de gestão, tudo com base nos seus objetivos.

Por força de Lei, o Plano de Manejo é um documento obrigatório para todas as Unidades de Conservação, devendo abranger, além da área da UC, a sua zona de amortecimento, os eventuais corredores ecológicos e as medidas visando a sua integração à economia e ao convívio das comunidades vizinhas, quando for o caso (DISTRITO FEDERAL, 2010).

No Distrito Federal, atualmente, existem 23 (vinte e três) Unidades de Conservação com Plano de Manejo aprovado e publicado $^{\S \S}$, além de 13 documentos em elaboração

visitação. LEUZINGER, Márcia Dieguez. Natureza e cultura: unidades de conservação de proteção integral e populações tradicionais residentes. Curitiba: Letra da Lei, 2009. p. 158.

${ }_{\S \S}^{\$}$ No site do IBRAM/DF, o número de Planos de Manejo é maior por contabilizar 4 (quatro) documentos referentes a áreas que não são reconhecidas legalmente como UCs. 
$(\text { IBRAM, 2020) })^{* * * *}$. Em 2017, porém, esse número era menor, pois só existiam 12 (doze) Plano de Manejo editados (SOUZA, 2017).

Houve, portanto, uma evolução bastante positiva dos números, principalmente, porque se trata de um documento técnico complexo que exige o "entendimento das questões ambientais, socioeconômicas, históricas e culturais que caracterizam uma UC e a região na qual ela se insere" (ICMBIO, 2019).

A existência de Plano de Manejo, além de ajudar a resguardar os atributos ambientais da área a que diz respeito, é de fundamental importância para a instalação das estruturas de gestão, como citado.

Assim, o ideal é que, ante a inexistência deste documento técnico, o Poder Público adote apenas as medidas estritamente necessárias à manutenção da integridade dos recursos naturais do espaço protegido, com base no princípio da precaução, que está calcado comumente na incerteza cientifica e na ameaça de dano (ONU, 1992), em que pese a Lei $\mathrm{n}^{\circ}$ 9.985/2000 fazer essa ressalva somente para as UCs de Proteção Integral.

Isso porque a busca pela efetividade do direito ao meio ambiente ecologicamente equilibrado não se exaure nos mandamentos expressos no artigo 225, da Constituição, notadamente no que tange à criação e gestão desses Espaços Territoriais Especialmente Protegidos.

$\mathrm{Na}$ verdade, esse dever contém "um mandamento de ordem negativa, consistente na não degradação, mas possui também uma disposição de cunho positivo, que impõe a todos Poder Público e coletividade - a prática de atos tendentes a recuperar, restaurar e defender o ambiente ecologicamente equilibrado" (STJ, 2011).

No caso do Distrito Federal, tanto a criação de novas UCs como os atos de gestão consubstanciados por meio da recategorização de diversas áreas no DF e da construção dos Planos de Manejo, são reflexos da busca pela concretização de ambos os mandamentos.

Muito ainda precisa ser feito, quando se trata da gestão das Unidades de Conservação, até porque as medidas destinadas à gestão desses espaços fazem parte de um processo contínuo de implantação e revisão.

\footnotetext{
**** Na página afeta aos Plano de Manejo no site do IBRAM/DF não consta o Parque Ecológico de Santa Maria. No dia 25 de março de 2020, no entanto, o ente ambiental noticiou a aprovação do Plano de Manejo da referida unidade, razão pela qual ele foi contabilizado neste trabalho (IBRAM, 2020).
} 


\section{Os retrocessos identificados no Sistema Distrital de Unidades de Conservação: manutenção de UCs sem a definição de poligonais e a inatividade dos Conselhos Gestores}

A criação de Unidades de Conservação, sem a indicação de limites georreferenciais, era uma prática comum antes da edição da Lei n 9.985/2000 (SOUZA, 2017). Antes disso, poucos diplomas legais versavam sobre o tema, como a Lei ${ }^{\circ} 6.902$ de 27 de abril de 1981 (BRASIL, 1981), o que dava margem a esse tipo de ação.

Selecionar áreas e definir os seus contornos legais não são tarefas fáceis. Bensusan (2006) esclarece que, no Brasil, as primeiras áreas foram selecionadas por causa das suas belezas naturais. Os critérios técnicos, como os fenômenos geológicos e geomorfológicos, alta concentração de endemismo, a presença de espécies raras ou ameaçadas, foram incorporados somente com o passar do tempo (BENSUSAN, 2006).

Com o advento do SNUC, no entanto, a indicação da poligonal, ou seja, dos limites espaciais das UCs, passou a ser obrigatória já nos estudos técnicos de criação. Tal medida obviamente foi replicada no âmbito da Lei Complementar $n^{\circ}$ 827/2010.

No Distrito Federal, após a instituição do Sistema Distrital de Conservação da Natureza, não foi criada nenhuma Unidade de Conservação sem a definição da poligonal. O Parque Ecológico de Águas Claras e o Parque Ecológico do Gama, por exemplo, recriados, respectivamente, nos anos de 2018 e 2019, já trouxeram, como a Lei exige, os seus limites legais.

Há, no entanto, 17 (dezessete) Unidades de Conservação das 73 (setenta e três) existentes, que foram intuídas ou recentemente recategorizadas, mas permanecem sem os seus limites definidos. São elas: Parque Ecológico dos Jequitibás (DISTRITO FEDERAL, 2017), Parque Ecológico do DER (DISTRITO FEDERAL, 1999), Parque Distrital dos Pequizeiros (DISTRITO FEDERAL, 2019), Área de Relevante Interesse Ecológico Cachoeira do Pipiripau (DISTRITO FEDERAL, 2019), Parque Ecológico e Vivencial da Lagoa Joaquim Medeiros (DISTRITO FEDERAL, 1998), Parque Distrital do Retirinho (DISTRITO FEDERAL, 2019), Refúgio de Vida Silvestre Mestre D'Armas (DISTRITO FEDERAL, 2019), Parque Ecológico Sucupira (DISTRITO FEDERAL, 2019), Parque Ecológico e Vivencial do Rio Descoberto (DISTRITO FEDERAL, 1993), Parque Ecológico e Vivencial Bosque dos Eucaliptos (DISTRITO FEDERAL, 1999), Parque Ecológico de Santa Maria 
(DISTRITO FEDERAL, 2019), Parque Distrital Recanto das Emas (DISTRITO FEDERAL, 2019), Refúgio de Vida Silvestre Garça Branca (DISTRITO FEDERAL, 2019), Parque Ecológico do Anfiteatro Natural do Lago Sul (DISTRITO FEDERAL, 2019), Refúgio de Vida Silvestre Morro do Careca (DISTRITO FEDERAL, 2019), Parque Ecológico dos Pioneiros (DISTRITO FEDERAL, 2019), e Parque Ecológico Areal (DISTRITO FEDERAL, 2019).

Todos esses espaços, porém, foram instituídos antes da Lei Complementar $\mathrm{n}^{\circ}$ 827/2010, que criou o Sistema Distrital de Unidades de Conservação da Natureza. Alguns sequer eram categorizados como Unidades de Conservação até as modificações normativas promovidas a partir de 2017. Assim, a criação dessas áreas, sem a definição precisa de seus limites, embora não seja recomendável, já que não pode proteger o que não se conhece, não pode ser considerada uma afronta ao SDUC.

Cabe ao Distrito Federal, no entanto, promover a regularização dessa situação visando resguardar a aplicação dos recursos de compensação ambiental, possibilitar o exercício da atividade fiscalizatória e implementar medidas efetivas de gestão.

O processo de delimitação dessas UCs, assim como outros problemas afetos a essas áreas, poderia ser democraticamente discutido, respeitados os critérios técnicos, com a sociedade por meio dos Conselhos Gestores, caso tais órgãos estivessem em operação.

Os Conselhos Gestores, que podem ser qualificados como fóruns "de excelência para promover o diálogo permanente com a sociedade e construir com as comunidades e demais atores locais a solução para os desafios a serem enfrentados pela gestão das Unidades de Conservação" (ICMBIO, 2014), são obrigatórios para todas as UCs pela inteligência das normas trazidas pelo SNUC e SDUC.

Ambos os Sistemas - Federal e Distrital - embora não cravem expressamente essa orientação, estabelecem como diretriz basilar o envolvimento da sociedade nas questões afetas às UCs. Isso porque a participação popular é uma das vigas de sustentação do sistema protetivo ambiental nacional e mundial.

No âmbito nacional, o primado da participação é, ao mesmo tempo, sustentáculo do Estado Democrático de Direito (FLORENCIO, 2013), e reflexo do direito ao meio ambiente equilibrado. O Superior Tribunal de Justiça já reconheceu que:

ADMINISTRATIVO. RECURSO ESPECIAL. DANO AMBIENTAL. CONDENAÇÃO. ART. $3^{\circ}$ DA LEI 7.347/85. CUMULATIVIDADE. POSSIBILIDADE. OBRIGAÇÃO DE FAZER OU NÃO FAZER COM 
INDENIZAÇÃO. RECURSO PARCIALMENTE PROVIDO. (...). 2. O meio ambiente equilibrado - elemento essencial à dignidade da pessoa humana -, como "bem de uso comum do povo e essencial à sadia qualidade de vida" (art. 225 da CF), integra o rol dos direitos fundamentais. 3. Tem o meio ambiente tutela jurídica respaldada por princípios específicos que lhe asseguram especial proteção. 4. O direito ambiental atua de forma a considerar, em primeiro plano, a prevenção, seguida da recuperação e, por fim, o ressarcimento. 5. Os instrumentos de tutela ambiental - extrajudicial e judicial - são orientados por seus princípios basilares, quais sejam, Princípio da Solidariedade Intergeracional, da Prevenção, da Precaução, do Poluidor-Pagador, da Informação, da Participação Comunitária, dentre outros, tendo aplicação em todas as ordens de trabalho (prevenção, reparação e ressarcimento). 6. "É firme o entendimento de que é cabível a cumulação de pedido de condenação em dinheiro e obrigação de fazer em sede de ação civil pública" (AgRg no REsp 1.170.532/MG). 7. Recurso especial parcialmente provido para, firmando o entendimento acerca da cumulatividade da condenação prevista no art. $3^{\circ}$ da Lei $7.347 / 85$, determinar o retorno dos autos ao Tribunal de origem para que fixe o quantum necessário e suficiente à espécie (STJ, 2011).

A nível mundial, o princípio da participação está insculpido, por exemplo, no artigo

10 da Declaração do Rio sobre o Meio Ambiente e Desenvolvimento:

a melhor maneira de tratar as questões ambientais é assegurar a participação, no nível apropriado, de todos os cidadãos interessados. No nível nacional, cada indivíduo terá acesso adequado às informações relativas ao meio ambiente de que disponham as autoridades públicas, inclusive informações acerca de materiais e atividades perigosas em suas comunidades, bem como a oportunidade de participar dos processos decisórios. Os Estados irão facilitar e estimular a conscientização e a participação popular, colocando as informações à disposição de todos. Será proporcionado o acesso efetivo a mecanismos judiciais e administrativos, inclusive no que se refere à compensação e reparação de dano. (ONU, 1992).

Assim, em sintonia com esses e outros regramentos, o princípio da participação passou a constar expressamente na maioria das normas ambientais como, por exemplo, a Lei Federal $n^{\circ}$ 9.985/00, que instituiu o SNUC, e a Lei Federal $n^{\circ} 12.305 / 10$, que dispõe sobre a Política Nacional de Resíduos Sólidos.

Por força do Decreto Federal no 4.340/02, que regulamenta o SNUC, a participação popular, quando se trata das Unidades de Conservação, é materializada por meio das consultas públicas necessárias à criação, recategorização das UCs e à construção dos Plano de Manejo, e dos Conselhos Gestores.

O artigo 17, da norma disciplinar citada, prevê, por exemplo, que as categorias de Unidade de Conservação, sem qualquer distinção quanto ao Grupo a qual pertencem, poderão ter, conselho consultivo ${ }^{\dagger \dagger \dagger}$ ou deliberativo, cuja presidência caberá ao chefe da unidade de

††† O Conselho Consultivo exara opiniões sobre assuntos relacionados à gestão da unidade de conservação enquanto o Conselho Deliberativo delibera, por meio de resoluções, sobre assuntos relacionados à gestão da

Rev. de Direito e Sustentabilidade | e-ISSN: 2525-9687 | Evento Virtual | v. 6 | n. 1 | p. 16-36 |

Jan/Jun. 2020 
conservação, o qual designará os demais conselheiros indicados pelos setores a serem representados.

A função de um Conselho Gestor é mover esforços para conservação, consecução dos objetivos, equacionamento de conflitos, compatibilização de interesses e integração do espaço ao qual se refere ao seu contexto local e regional (ICMBIO, 2014). O Conselho Gestor é, portanto, um órgão no qual são debatidos temas afetos à Unidade de Conservação pelo Poder Públicos, pela comunidade cientifica, entidades civis e sociedade, de um modo geral, numa espécie de concretização máxima do primado da transparência.

No âmbito federal, os Conselhos Gestores são uma realidade. Das 334 (trezentos e trinta e quatro) Unidades de Conservação federais existentes, 285 (duzentos e oitenta e cinco) possuem Conselho Gestor (ICMBIO, 2020).

No caso do Distrito Federal, contudo, a situação é absolutamente distinta. Isso porque das 73 (setenta e três) UCs, apenas, 2 (duas) possuem Conselho Gestor formalmente instituído: Parque Ecológico Burle Marx (DISTRITO FEDERAL, 2016) e a Área de Relevante Interesse Ecológico Granja do Ipê (DISTRITO FEDERAL, 2016).

No momento, porém, esses dois colegiados não estão em funcionamento (SEMA, 2020). Por meio da Lei de Acesso à Informação, a Secretaria de Estado de Meio Ambiente do Distrito Federal esclareceu que está movendo esforços para retomar o funcionamento desses dois Conselhos. Quanto às demais UCs, a informação é de que existe uma proposta de agrupamento, levando-se em consideração a categoria e a localização desses espaços, para se instituir Conselhos Gestores que abarquem mais de uma Unidade de Conservação. A justificativa é que existe uma limitação na estrutura administrativa, além de uma grande quantidade de UCs (SEMA, 2020).

Desde 2019, no entanto, com o advento do Decreto $\mathrm{n}^{\circ}$ 39.717, datado de 19 de março, os Conselhos Gestores das UCs do DF passaram a ser vinculados à Secretaria de Estado de Meio Ambiente. Tal iniciativa, no entanto, conflita com a Lei $n^{\circ} 3.984$, de 28 de maio de 2007, que estabelece como competência do Instituto Brasília Ambiental IBRAM/DF a gestão das UCs do DF, o que certamente inclui os seus Conselhos, e o próprio SDUC - Lei Complementar $n^{\circ} 827$, de 22 de julho de 2010, o qual atribui a presidência desses

unidade de conservação. ICMBIO. Conselhos Gestores de Unidades de Conservação Federais. Disponível em: https://www.icmbio.gov.br/portal/images/stories/comunicacao/publicacoes/guia-conselhos-2014.pdf. Acesso em: $1^{\circ}$ abr. 2020. 
colegiados ao ente executor, in casu, o IBRAM/DF. Não se tem notícias, no entanto, de qualquer questionamento sobre a referida norma.

A instituição dos Conselhos Gestores, o processo de definição das poligonais inexistentes, a edição e atualização dos Planos de Manejo, a conclusão da recategorização, a recriação das quatro áreas que tiveram seus atos institutivos declarados inconstitucionais ${ }^{\dagger+t}$, assim como o equacionamento de outros problemas relacionados à regularização dominial e à implementação da infraestrutura mínima necessária de uso e gestão são os grandes desafios a serem enfrentados para a consolidação efetiva das Unidades de Conservação do Distrito Federal (SOUZA, 2017).

Tal missão, porém, não deve ficar restrita ao Poder Público. A sociedade civil e as demais instituições públicas e privadas também possuem um papel importante na busca pela sustentabilidade desses espaços.

\section{Conclusão}

A instituição de Unidades de Conservação passou a ser apoiada com mais veemência quando o homem se deu conta de que o uso desenfreado dos recursos naturais poderia gerar um colapso irremediável. Assim, esses espaços, desde sua origem, sempre estiveram associados à noção de sustentabilidade.

No Brasil, a criação e a gestão das Unidades de Conservação, que é apenas uma das espécies de Espaços Territoriais Especialmente protegidos existentes, passou a ser regida pela Lei $n^{\circ} 9.985$, de 18 de julho de 2000.

Além de unificar conceitos, diretrizes, princípios e as categorias de manejo das Unidades de Conservação, o SNUC permitiu, em consonância com a previsão inserida no artigo 225, da Constituição, que as diversas esferas estatais também instituíssem os seus próprios sistemas protetivos.

O Distrito Federal, seguindo essa premissa, editou a Lei Complementar $n^{\circ} 827$, de 22 de julho de 2010, responsável por criar o Sistema Distrital de Unidades de Conservação da Natureza - SDUC.

Wt Parque Recreativo Taguatinga, Parque Ecológico e Vivencial Sobradinho, Parque Ecológico da Cachoeirinha, Parque Recreativo e Ecológico Canela de Ema (SOUZA, 2017). 
Em 2020, o SDUC completa 10 anos! Muitos avanços ocorreram nesse período como a adequação da nomenclatura de diversas áreas àquelas previstas na Lei Complementar $\mathrm{n}^{\circ}$ 827/10. Lei Complementar $n^{\circ}$ 827, a construção dos Planos de Manejo e a recriação de duas novas unidades que tiverem seus atos constitutivos declarados inconstitucionais.

Concomitantemente, no entanto, aconteceram algumas involuções como a manutenção de diversas UCs sem a definição de seus limites e o não funcionamento dos dois únicos conselhos gestores instituídos. Além disso, não houve progresso com relação a criação de novos Conselhos Gestores, em que pese à participação popular ser uma das diretrizes do sistema protetivo brasileiro.

Os desafios ainda são imensos porque, além desses problemas, outros precisam ser equacionados como a edição dos Planos de Manejo faltantes, a finalização do processo de recategorização, a recriação das quatro áreas que tiveram seus atos institutivos declarados inconstitucionais, a regularização dominial e a instalação das estruturas de uso e gestão das UCs.

Não se trata, porém, de uma obrigação exclusiva do Estado. Todos devem se empenhar nesse processo que tem como pano de fundo a concretização do direito ao meio ambiente ecologicamente equilibrado.

\section{Referências}

BRASIL. Lei $n^{\circ}$ 9.985, de 18 de julho de 2000. Dispõe sobre a regulamentação do art. 225, $\S$ $1^{\circ}$, incisos I, II, III e VII da Constituição Federal, institui o Sistema Nacional de Unidades de Conservação da Natureza e dá outras providências. Disponível em:<http://www.planalto.gov.br/ccivil_03/leis/L9985.htm>. Acesso em: 20 mar. 2020.

BRASIL. Lei $\mathrm{n}^{\mathrm{o}}$ 6.902, de 27 de abril de 1981. Disponível em:< https://www.planalto.gov.br/CCivil_03/Leis/L6902.htm>. Acesso em: 31 mar. 2020.

BRASIL. Decreto $\mathrm{n}^{\mathrm{o}}$ 4.340, de 22 de agosto de 2002. Disponível em: http://www.planalto.gov.br/ccivil_03/decreto/2002/D4340.htm. Acesso em: $1^{\text {o }}$ abr. 2020.

BRUNDTLAND, G. H. (Org.) nosso futuro comum. Rio de Janeiro: FGV, 1987. 
DIEGUES, Antônio Carlos Santana. O mito da natureza intocada. 4. Ed. São Paulo: Annablume, Nupaub e Hucitec, 2002.

ESTRELA, Carina; POTT, Crisla. Histórico ambiental: desastres ambientais e o despertar de um novo pensamento. Disponível em: http://www.scielo.br/pdf/ea/v31n89/0103-4014-ea-3189-0271.pdf. Acesso em: 20 mar. 2020.

DISTRITO FEDERAL. Decreto n ${ }^{\circ}$ 39. 607, de 31 de dezembro de 2018. Disponível em: http://www.sinj.df.gov.br/sinj/Norma/e19f2f0ea9e241b48e437c4a473b1a14/Decreto_39607_ 31_12_2018.html. Acesso em: 25 mar. 2020.

DISTRITO FEDERAL. Lei $\mathrm{n}^{\circ}$ 041/89. Disponível em:< http://legislacao.cl.df.gov.br/Legislacao/consultaTextoLeiParaNormaJuridicaNJUR126831!bu scarTextoLeiParaNormaJuridicaNJUR.action>. Acesso em:17 mar. 2020.

DISTRITO FEDERAL. Lei Complementar $n^{\circ} 827$, de 22 de julho de 2000. Dispõe sobre a regulamentação do art. 279, I, III, IV, XIV, XVI, XIX, XXI, XXII, e o art. 281 da Lei Orgânica do Distrito Federal, institui o Sistema Distrital de Unidades de Conservação da Natureza - SDUC e dá outras providências. Disponível em:< http://legislacao.cl.df.gov.br/Legislacao/consultaTextoLeiParaNormaJuridicaNJUR193856!buscarTextoLeiParaNormaJuridicaNJUR.action>. Acesso em: 10 mar. 2020.

DISTRITO FEDERAL. Decreto $\mathrm{n}^{\circ}$ 16.239, de 28 de dezembro de 1994. Disponível em: http://www.sinj.df.gov.br/sinj/Norma/27332/Decreto_16239_28_12_1994.html. Acesso em: 25 mar. 2020.

DISTRITO FEDERAL. Lei $\mathrm{n}^{\circ}$ 2.312, de 11 de fevereiro de 1999. Disponível em: http://www.sinj.df.gov.br/sinj/Norma/50270/Lei_2312_11_02_1999.html. Acesso em: 25 mar. 2020. 
DISTRITO FEDERAL. Lei $\mathrm{n}^{\mathrm{o}}$ 6.414, de 3 de dezembro de 2019. Disponível em: http://www.sinj.df.gov.br/sinj/Norma/47a3d7c4ff6b4997868f22b5851ecb27/Lei_6414_03_12 _2019.html. Acesso em: 25 mar. 2020.

DISTRITO FEDERAL. Lei $\mathrm{n}^{\circ}$ 2.247, de 31 de dezembro de 1998. Disponível em: http://www.sinj.df.gov.br/sinj/Norma/50206/Lei_2247_31_12_1998.html. Acesso em: 25 mar. 2020.

DISTRITO FEDERAL. Lei Complementar no 955, de 28 de novembro de 2019. Disponível em:http://www.sinj.df.gov.br/sinj/Norma/01f816e252604acb92b1f8b4bc1accfc/Lei_Comple mentar_955_28_11_2019.html. Acesso em: 25 mar. 2020.

DISTRITO FEDERAL. Lei $\mathrm{n}^{\circ}$ 547, de 23 de setembro de 1993. Disponível em: http://www.sinj.df.gov.br/sinj/Norma/48506/Lei_547_23_09_1993.html. Acesso em: 25 mar. 2020.

DISTRITO FEDERAL. Lei $\mathrm{n}^{\mathrm{o}}$ 2.014, de 28 de julho de 1998. Disponível em: http://www.sinj.df.gov.br/sinj/Norma/49973/Lei_2014_28_07_1998.html. Acesso em: 25 mar. 2020.

DISTRITO FEDERAL. Decreto $\mathrm{n}^{\circ}$ 40.116, de 21 de março de 2016. Disponível em: http://www.sinj.df.gov.br/sinj/Norma/7b7ace61ed414bf89795f059c1b41b72/Decreto_37198_ 21_03_2016.html. Acesso em: 25 mar. 2020.

DISTRITO FEDERAL. Decreto $\mathrm{n}^{\mathrm{o}}$ 37.198, de 19 de setembro de 2016. Disponível em: http://www.sinj.df.gov.br/sinj/Norma/ed7ae618885b46958916d520c514ca25/Decreto_40116 _19_09_2019.html. Acesso em: 25 mar. 2020.

DISTRITO FEDERAL. Decreto $\mathrm{n}^{\mathrm{o}}$ 37.274, de 22 de abril de 2016. Disponível em: http://www.sinj.df.gov.br/sinj/Norma/a951660eac424eacbfdc508fba92f0bb/Decreto_37274_2 2_04_2016.html. Acesso em: 25 mar. 2020. 
FLORENCIO, Marcela Proença Alves. Princípios da Publicidade e Participação Popular: Bases Estruturantes para a Transparência na Administração Pública. Disponível em: https://periodicos.ufpe.br/revistas/RMP/article/view/320. Acesso em: $1^{\text {o }}$ abr. 2020.

IBRAM. Parecer Técnico $\mathrm{n}^{\mathrm{o}}$ 500.000.001/2014-Sugap/Ibram. Disponível em: http://www.ibram.df.gov.br/images/Arquivos\%20site/1.Parecer\%20Final\%20Recategorizacao .pdf. Acesso em: 24 mar. 2020.

IBRAM. Unidades de Conservação. Disponível em: http://www.ibram.df.gov.br/unidades-deconservacao/. Acesso em: 27 mar. 2020.

IBRAM. Plano de Manejo. Disponível em: http://www.ibram.df.gov.br/plano-de-manejo/. Acesso em: 30 mar. 2020.

IBRAM. Aprovado Plano de Manejo do Parque Ecológico de Santa Maria. Disponível em: http://www.ibram.df.gov.br/aprovado-plano-de-manejo-do-parque-ecologico-de-santa-maria/. Acesso em: 30 mar. 2020.

ICMBIO. Curso aborda plano de manejo de unidades de conservação. Disponível em: https://www.icmbio.gov.br/portal/ultimas-noticias/20-geral/10266-curso-aborda-plano-demanejo-de-unidades-de-conservacao. Acesso em: 31 mar. 2020.

ICMBIO. Conselhos Gestores de Unidades de Conservação Federais. Disponível em: https://www.icmbio.gov.br/portal/images/stories/comunicacao/publicacoes/guia-conselhos2014.pdf. Acesso em: $1^{\circ}$ abr. 2020.

ICMBIO. Painel Dinâmico. Disponível http://qv.icmbio.gov.br/QvAJAXZfc/opendoc2.htm?document=painel_corporativo_6476.qvw \&host=Local\&anonymous=true. Acesso em: 3 abr. 2020.

LEUZINGER, Márcia; SOUZA, Lorene. A SUBUTILIZAÇÃO DA EDUCAÇÃO AMBIENTAL NO COMBATE À CRISE HÍDRICA. In: XXVIII Encontro Nacional do 
CONPEDI, Goiânia, Brasil. Disponível em: http://conpedi.danilolr.info/publicacoes/no85g2cd/rw0mwt95/Z9C1j70fnTw3JyrA.pdf. Acesso em: 3 abr. 2020.

LEUZINGER, M. D. Uso Público em Unidades de Conservação. In: CONGRESSO DO MAGISTÉRIO SUPERIOR DE DIREITO AMBIENTAL DA APRODAB E CONGRESSO DE DIREITO AMBIENTAL DA PUC-RIO, 8. 2010, Rio de Janeiro. Anais... Rio de Janeiro: PUC, 2010.

LAYRARGUES, Philippe Pomier. Do ecodesenvolvimento ao desenvolvimento sustentável: evolução de um conceito? Proposta, Rio de Janeiro, v. 24, n. 71, p. 1-5, fev. 1997. https://lieas.fe.ufrj.br/download/artigos/ARTIGOECODESENVOLVIMENTO_DESENVOL VIMENTO_SUSTENTAVEL-.pdf. Acesso em: 20 mar. 2020.

MPDFT. Ministério Público apoia consulta pública de recategorização dos parques ecológicos do DF. Disponível em: https://www.mpdft.mp.br/portal/index.php/comunicacaomenu/noticias/noticias-2015/noticias-2015-lista/7909-ministerio-publico-apoia-consultapublica-de-recategorizacao-dos-parques-ecologicos-do-df. Acesso em: 24 mar. 2020.

ONU. Reporto of the United Nations Conference on the Human Environmet. 1972. Disponível em: http://www.un-documents.net/aconf48-14r1.pdf. Acesso em: 20 mar. 2020.

ONU. Declaração do Rio sobre meio ambiente e desenvolvimento. Disponível em:< http://www.stf.jus.br/arquivo/cms/publicacaoRTJ/anexo/224_1.pdf >. Acesso em: 10 mar. 2020.

SACHS, Ignacy. Caminhos para o desenvolvimento sustentável. Rio de Janeiro: Garamond, 2009.

SEMA. Pedido de Acesso à Informação nº 00393000008202051 , respondido no dia 30 de março de 2020. 
SOUZA, Lorene Raquel. A Gestão das Unidades de Conservação do Distrito Federal. Dissertação (Mestrado) Centro Universitário de Brasília. Programa de Mestrado em Direito, 2017.

Disponível em:

https://www.uniceub.br/arquivo/144ng_20190710103628*pdf?AID=2923. Acesso em: 21 mar. 2020.

TJDFT. DF deve recategorizar unidades de conservação e evitar riscos ambientais. Disponível em: https://www.tjdft.jus.br/institucional/imprensa/noticias/2020/janeiro/justica-determinaque-df-execute-plano-de-recategorizacao-das-unidades-de-conservacao. Acesso em: 25 mar. 2020.

STJ. REsp 1.071.741/SP, Segunda Turma, Rel. Min. Herman Benjamin. Disponível em: <https://ww2.stj.jus.br/docs_internet/revista/eletronica/stjrevistaeletronica2015_239_1_capUn idadedeConservacao.pdf>. Acesso em: 17 de mar. 2020.

STJ. RESP nº 1.163.524/SC, Segunda Turma, Rel. Min. Humberto Martins. Disponível em: https://ww2.stj.jus.br/processo/revista/inteiroteor/?num_registro=200902066034\&dt_publicac ao=12/05/2011. Acesso em: 31 mar. 2020.

STJ. RECURSO ESPECIAL $\mathrm{N}^{\circ}$ 1.115.555/MG. Disponível em: https://ww2.stj.jus.br/processo/revista/inteiroteor/?num_registro=200900040611\&dt_publicac ao=23/02/2011. Acesso em: 2 abr. 2020. 